\title{
Relevance of the Indicators Observed in the Measurement of Social Resilience
}

\author{
Ida Brou ASSIE \\ UFR Mathématiques et Informatique \\ Université Félix Houphouët Boigny \\ Abidjan, Côte d'Ivoire
}

Amadou SAWADOGO

UFR Mathématiques et Informatique Université Félix Houphouët Boigny

Abidjan, Côte d'Ivoire

\author{
Jérôme K. ADOU \\ UFR Mathématiques et Informatique \\ Université Félix Houphouët Boigny \\ Abidjan, Côte d'Ivoire
}

\author{
Souleymane OUMTANAGA \\ Institut Polytechnique Houphouët Boigny \\ Yamoussoukro, Côte d'Ivoire
}

\begin{abstract}
This article scrutinizes the validation of the observed properties by the experts in the study of social resilience. To that purpose, it utilizes the method of factorial analysis of multi-correspondences (ACM) in the reflections and practices of observatories about impact strength. Furthermore, a mathematical modeling of the concept of social resilience, a description of databases of the observatory of impact strength are made in understanding the process of analysis of impact strength of an individual.
\end{abstract}

Keywords-Social resilience; observatory of social resilience; mathematical modeling of the resilience; analysis of multicorrespondences (ACM)

\section{INTRODUCTION}

In recent years, the social resilience is a subject of several discussions in the field of social sciences. But, there are numerous conferences, and colloquiums chiefly about its operationalization, this concept must define globally as human abilities to overcome the suffering. So, the resilience stays henceforth the main theme of donors and humanitarian aid actors. ${ }^{1}$ In this context, it is useful to identify properties of resilience (observed elements, features of the resilience of communities) for investment policies. Now, the identification of these elements produces joint problems.

- The first concern is based on the pertinence of properties of impact strength chosen by researcher in the study of social resilience. Indeed, the study of social resilience being complex, each property in relation with its core goal defines its properties of social resilience. That's where the interest substantiates the pertinence of these properties to demonstrate the set of chosen properties represents a pertinent set of properties of resilience. Let us qualify this study, the fundamental set of impact strength.

- The second problem contributes to build a mathematical modeling of social resilience for a better understanding of phenomenon.

\footnotetext{
${ }^{1}$ http://resiliences.univ-lille1.fr /Resilience and humanitarian action, 2014.[Online]
}

Trying to answer this concern, we describe in this paper the chosen properties of resilience and a methodology of check of the relevant properties in applying the statistical method of the ACM [1] about data files of the Observatory for reserve properties in Section 2. The Section 3 describes the mathematical modeling.

\section{DESCRIPTION OF PROPERTIES OF RESILIENCE STUDY AND RELEVANCE OF THESE PROPERTIES OF RESILIENCE}

Facing with several natural or man-made disasters, UMI Resilience $^{2}$ (International Mixed Unit Resilience) of Institute for Research Development (IRD) sets itself the goal to increase the knowledge on the social environmental and social dynamics of fragility, adaptation, and retrieving. ${ }^{3}$ Thus, the monitoring centers in different areas with specific themes to answer to the expectations of several development structures have been created. In 1995, rural observatories of Madagascar are set up. In 2014, 5th International conference of UMI Resilience in Bouake ${ }^{4}$ has laid the foundations of the observatory of impact strength of Côte d'Ivoire in post crisis context. These are better frameworks of analysis and reflections on social resilience. Indeed, concerning these observatories, UMI Resilience examines the implemented strategies by population, families, and communities. These strategies are implemented to adapt oneself and to survive, when these populations have been affected by change or shocks that are economic, social, environmental as well as political nature.

Besides, the impact strength observatory investigates the resources that individuals of given community tormented by a crisis have developed to get by. It has fostered and continues to be an important data on the observed properties of social resilience. Depending on the targeted audience by these actors of monitoring centers, these are several heterogeneous databases that are settled to study the resilience of people.

\footnotetext{
${ }^{2}$ Founded on 1 January 2012, the UMI Resiliencies is the result of a double tutelage CIRES/ IRD. http://www.resiliences.ird.fr

${ }^{3} \mathrm{http}: / /$ www.resiliences.ird.fr

${ }^{4}$ City located in the center of Côte d'Ivoire
} 
However, these actors of observatories propose the solutions taking into account the set of elements such as:

- Properties of resilience: The characteristics to be considered for the study of social resilience. These properties describe dimensions of resilience.

- Targeted audience: People or communities whose the properties are experienced.

- The data of study: The results of inquiries.

According to their studies, different researchers identified factors of resilience. These are numerous and similar [2]. This is why; it is useful to justify the choice of indicators of social resilience about the study to lead. It demonstrates the relevance of the set of indicators of resilience about study of the social resilience.

From an examination of Ivorian context of post electoral crisis, there are lots of data which have been collected in the framework of this project "observatory of resilience of Bouaké", measurement approach and some results in this region of country. Despite the experienced events of 2010 in Côte d'Ivoire, these data enquire into the satisfaction of surveyed individuals on their new lives. Hundred and one people have constituted the sample of study. Indeed, the analysis of obtained data by the actors of this observatory leads to an approach of measure of resilience. This approach of measurement contributes to consider the various factors on the social resilience about this city [3]. Besides, what is and continues to be, appears to us that some problems met by youngster like the teens phenomenon "Microbes" 5 " can be explained by psychological problems. As a result, we choose the properties of resilience registered in Table 1.

These must be summarized in personal and social dimensions of an interviewee. The properties are respectively a set of variables which pave the way for recognizing the abilities of an individual to begin a new life when a trauma appears and to perceive how an individual integrates its immediate environment despite the shock. These are qualitative ordinals.

These properties are related to psychology of people, underwent a trauma in Kouadio-Odounfa's works [3]. Indeed, the economic aspects of resilience have been discussed in the literature. Let us quote [3]-[6], [9].

These 14 properties define the fundamental set of resilience denoted $U=\left\{u^{j}, 1 \leq j \leq 14\right\}$ in the context of our study. To prove the relevance of $U$, we need to study the connections between its components.

Let us take $u^{j} \epsilon U$ with $j=1, \ldots, 14$, one of properties of studied impact strength. We assume that the property $u^{j}$ has $q_{j}$ modalities denoted by $m_{k}^{u^{j}}, k=1, \ldots, q_{j}$ with $M=$ $\left\{m_{k}^{u^{j}}, 1 \leq j \leq 14,1 \leq k \leq q_{j}\right\}$. We pose $Q=\sum_{j=1}^{14} q_{j}^{u^{j}}$, the

${ }^{5}$ Children in conflict with the law according to the Ministry of Human Rights and Civil Liberties of Côte d'Ivoire, during the 31st Session of the Human Rights Council of the UN, from 29 February to 24 March 2016 in

Geneva.http://bice.org/fr/31eme-session-conseil-droits-de-lhomme-onu/ total number of modalities of $u^{j}$, where $q_{j=1, \ldots, 14}^{u^{j}}$ represents the cardinality of modalities $u^{j}$.

The data relating to observations of the resilience properties on the individuals of specimen $\Omega$ of size $n$ of the studied population are shown by,

$$
L=\left[L_{1} \ldots L_{j}\right] \text {, type }(n, Q) .
$$

where, $j=1, \ldots, 14$ and $L_{j}$ a logical table showing the observations of property $u^{j}$ of $n$ individuals of specimen $\Omega$. Let us mention $u_{i}^{j} \in M$, the value of property $u^{j}$ for an individual $i$. The logical table $L_{j}$ is defined by,

$$
L_{j}=\left[\delta_{k}^{u^{j}}\left(m_{l}^{u^{j}}\right)\right]_{i=1, \ldots, n}^{k=1, \ldots, q_{j}, j=1, \ldots, 14}
$$

where $\delta_{k}^{u^{j}}$, the application of a set $M$ of $u^{j}$ of values in the pair $\{0,1\}$ defined by:

$$
\delta_{k}^{u^{j}}\left(m_{l}^{u^{j}}\right)=\left\{\begin{array}{l}
0 \text { sil } \neq k \\
1 \text { sil }=k
\end{array} \text { with } m_{l}^{u^{j}} \equiv u_{i}^{j} \in M, i \epsilon \Omega .\right.
$$

One cannot have a unique value of properties $u^{j}$ reflected on all individualie $\Omega$. Thus, the implementation of correlations between the properties taken two by two is made from Burt's table [8] obtained by following formula 4 in which an excerpt is shown by Table 2 .

$$
B={ }^{t} L L
$$

Each property splits up into several sub-properties corresponding to its modalities. It partitions the size of people into $q_{j=1, \ldots, 14}^{u^{j}}$ groups depending on the modalities of each considered property. Indeed, each person belongs to a different group relative to the modalities of considered property of resilience.

The examination of the relevance of the resilience properties takes into account the description of connections two-by-two between 14 properties from the different groups of people concerning their modalities. The display of the matrix of correlation between these different properties in figure (Fig. 1) below, highlights the intensity existed between these properties taken two-by-two:

We take into account the size of the sample of this study. The correlations coefficients have been expressed by the size of the circles and the intensity of the colors (blue, for positive and red correlations, for negative correlations). The properties, defined in this sample, are appeared linked.

According to Fig. 1, the reliance observed between the properties confirms the set of variables. It forms the fundamental set of resiliencies. In fact, we can apply the properties of this set to assess a value of the resilience. As well, the manner of doing contributes to present a confirmatory approach in the case of researcher has theoretical prejudices on the choice of properties for its study. 
TABLE I. TABLE OF DESCRIPTION OF SELECTED PROPERTIES OF RESILIENCE

\begin{tabular}{|c|c|c|c|c|}
\hline Dimension & Property or indicator & Encoding & Description & Modality \\
\hline & Humor & Hum & $\begin{array}{l}\text { Ability to analyze the events. In psychology, it dealt with Coping } \\
\text { strategies }\end{array}$ & $\begin{array}{l}\text { Very low; Low; Medium; High; } \\
\text { Very high }\end{array}$ \\
\hline & $\begin{array}{l}\text { Optimism/fighting } \\
\text { spirit }\end{array}$ & Opt & To stay positive. & $\begin{array}{l}\text { Very low, Low, Medium, High, } \\
\text { Very high }\end{array}$ \\
\hline & Degree of autonomy & Deg & Independence. & $\begin{array}{l}\text { Very low, Low, Medium, High, } \\
\text { Very high }\end{array}$ \\
\hline & Self-control & Con & Control of feelings & $\begin{array}{l}\text { Very low, Low, Medium, High, } \\
\text { Very high }\end{array}$ \\
\hline & Representation & Rep & Interpretation of facts, situations. & $\begin{array}{l}\text { Very low, Low, Medium, High, } \\
\text { Very high }\end{array}$ \\
\hline & Creativity & Cre & To have a perception of life. & $\begin{array}{l}\text { Very low, Low, Medium, High, } \\
\text { Very high }\end{array}$ \\
\hline & Experience & Exp & What it has been experienced in the past. & $\begin{array}{l}\text { Very low, Low, Medium, High, } \\
\text { Very high }\end{array}$ \\
\hline & Health & Eta & Physical health, psychological health. & $\begin{array}{l}\text { Very low, Low, Medium, High, } \\
\text { Very high }\end{array}$ \\
\hline & Altruism & Alt & Desirability. & $\begin{array}{l}\text { Very low, Low, Medium, High, } \\
\text { Very high }\end{array}$ \\
\hline & Grade & Gra & Level of Education. & Primary, Graduate, High \\
\hline \multirow{3}{*}{ Social } & $\begin{array}{l}\text { Cohesion/ Brother } \\
\text { Hood }\end{array}$ & Coh & Togetherness. & $\begin{array}{l}\text { Very low, Low, Medium, High, } \\
\text { Very high }\end{array}$ \\
\hline & Belief & Bel & What we believe. & $\begin{array}{l}\text { Very low, Low, Medium, High, } \\
\text { Very high }\end{array}$ \\
\hline & Relational network & Res & $\begin{array}{l}\text { Environment or living, job, education conditions, constituting an } \\
\text { external support. }\end{array}$ & $\begin{array}{l}\text { Very low, Low, Medium, High, } \\
\text { Very high }\end{array}$ \\
\hline
\end{tabular}

TABLE II. EXTRACT OF BURT's TABLE OBSERVEd PROPERTIES EST, HUM AND OPT UNDER THE SOFTWARE R

\begin{tabular}{|l|c|c|c|c|c|c|}
\hline & Est.0 & Est.1 & Est.2 & Est.3 & Est.4 & Est.5 \\
\hline Est.0 & 5 & 0 & 0 & 0 & 0 & 0 \\
\hline Est.1 & 0 & 2 & 0 & 0 & 0 & 0 \\
\hline Est.2 & 0 & 0 & 5 & 0 & 0 & 0 \\
\hline Est.3 & 0 & 0 & 0 & 18 & 0 & 0 \\
\hline Est.4 & 0 & 0 & 0 & 0 & 51 & 0 \\
\hline Est.5 & 0 & 0 & 0 & 0 & 0 & 20 \\
\hline Hum.0 & 3 & 0 & 0 & 0 & 0 & 0 \\
\hline Hum.1 & 0 & 0 & 0 & 0 & 0 & 0 \\
\hline Hum.2 & 0 & 1 & 2 & 5 & 5 & 1 \\
\hline Hum.3 & 0 & 0 & 2 & 4 & 15 & 4 \\
\hline Hum.4 & 1 & 1 & 1 & 2 & 25 & 2 \\
\hline Hum.5 & 1 & 0 & 0 & 7 & 6 & 12 \\
\hline Opt.0 & 1 & 0 & 0 & 0 & 0 & 0 \\
\hline
\end{tabular}

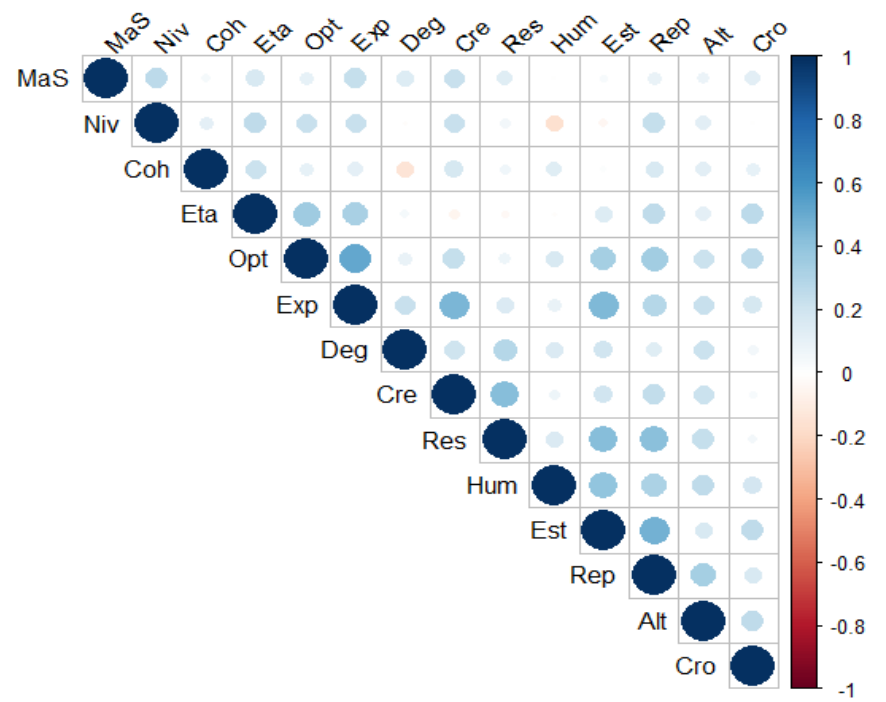

Fig. 1. Visualization of correlations between observed properties. 


\section{MATHEMATICAL Modelling OF CHARACTERIZATION OF RESILIENCE}

The operationalization of this concept of social resilience requires lots of symposia, conferences for instance the ATM ${ }^{6}$ days are consistently held a year. Unfortunately, at the international scale, no real mathematical theory was being established between researchers, policy makers, and those responsible for these structures on which the most important is to define the resilience profile of a lambda individual in a given population. As such, a modelling of social resilience will be needed to describe and explain this phenomenon as poverty in [7] from the fundamental set of resiliencies called $U$.

Let us take shock $C_{0}$ occurring at the time $t_{0}$ and the triplet ( $\left.\Omega, X,\left[t_{0}, \mathrm{~T}\right]\right)$ where $\Omega$ is representative sample of the population of persons, $X$ represents the set of studied properties of resilience studied on the individuals of the sample $\Omega$ and $\left[t_{0}, \mathrm{~T}\right]$, the interval of time on which individuals are observed and, $D$ the spatial domain on which individuals in the study population are located.

Let $U$ be, a restriction of $\mathrm{X}$ showing a set of relevant properties of resilience called the fundamental set of resiliencies. To a property of resilience $u^{j} \epsilon U$ with $j=1, \ldots, 14$, we define the following function:

$$
u^{j}: \Omega \times\left[t_{0}, T\right] \times D \rightarrow M,(i, t, x) \mapsto u^{j}(i, t, x) \equiv u_{i}^{j}(t, x) \ldots
$$

where, $M=\left\{m_{k}^{u^{j}}, 1 \leq j \leq 14, k=1: q_{j}\right\}$ is the set of modalities of the property of resilience $u^{j}$ considered, depicted in the table below (Tab.3) and $\mu\left(u_{i}^{j}(t, x)\right)$, the modality of the property $u^{j}$ closed to an individual $i$ in position $x$ at time $t$.

To carry on a digital processing of collected data for all individual of the sample, we associate with each different modalities digital value to reflect the response of an individual of sample of study. This value represents the measurement of resilience of individual $i$ of the sample $\Omega$ to the property of resilience $u^{j}$ of $U$ considered. It is defined by the following function $\mu$ :

$$
\mu: M \rightarrow[0,1], \quad u_{i}^{j}(t, x) \mapsto \mu\left(u_{i}^{j}(t, x)\right) .
$$

Thus, the measurement of resilience $\mu\left(u_{i}^{j}(t, x)\right)$ corresponding to each modality of $u^{j}$, for all individual $i$ of the sample $\Omega$ coming in position $x$ at time $t$ is given by Table 3 :

TABLE III. RELATION BETWEEN MODALITIES OF $u^{j}$ AND THE MEASUREMENT OF RESILIENCE

\begin{tabular}{|l|c|}
\hline $\boldsymbol{M}$, set of modalities of $\boldsymbol{u}^{\boldsymbol{j}}$ & $\boldsymbol{\mu}\left(\boldsymbol{u}_{\boldsymbol{i}}^{\boldsymbol{j}}(\boldsymbol{t}, \boldsymbol{x})\right)$ \\
\hline Very low & $P$ \\
\hline Low & $2 P$ \\
\hline Medium & $3 P$ \\
\hline High & $4 P$ \\
\hline Very high & $5 P$ \\
\hline
\end{tabular}

\footnotetext{
${ }^{6}$ http://www.mondesendeveloppement.eu/pages/association-tiers-monde
}

where, $\mathrm{P}=\frac{1}{\operatorname{card} M}$.

Despite the study on social resilience to involve the space and time, we are interested in its evolution during time. Thus, we confirm the hypothesis that the measurement of social resilience proposed is solely related to time. We consider it as "homogeneous resilience" that is:

$$
\forall i \in \Omega, \mu\left(u_{i}^{j}(t, x)\right) \equiv \mu\left(u_{i}^{j}(t)\right) .
$$

Abilities to overcome suffering, the impact strength of an individual can be described by a short or long-term process according to the individual. That is why, we can mention the notion of the adaptation of an individual $i \in \Omega$ underwent a shock $C_{0}$. So, we define the time of adaptability of an individual denoted $t_{a}$, as the time where this individual accepts his new life. At this time $t_{a}$, the function $\mu\left(u_{i}^{j}(t)\right)$ increases a local minimum. To consider shock $C_{0}$ occurring at time $t_{0}$, we establish the adaptability by the formula 8 . It is said that the individual $i$ is adaptable to $C_{0}$, if:

$\exists t_{a} \geq t_{0}$ like $\mu\left(u_{i}^{j}(t)\right)$ shows a local minimum for $t=t_{a}$, that is:

$$
\begin{gathered}
\left.\exists \delta>0 \text { such as, } \forall t \geq t_{0}, t \epsilon\right] t_{a}-\delta, t_{a}+\delta[, \\
\mu\left(u_{i}^{j}\left(t_{a}\right)\right) \leq \mu\left(u_{i}^{j}(t)\right)
\end{gathered}
$$

To reflect on the characterization of the adaptability of an individual, the definition of the criterion of resilience follows. It is said that an individual $i \in \Omega$ is resilient at $C_{0}$ in the context of our study, if:

$$
\exists t^{*} \geq t_{a} \text { such as } \mu\left(u_{i}^{j}\left(t^{*}\right)\right) \geq \mu\left(u_{i}^{j}\left(t_{a}\right)\right) .
$$

This explains the resilience of individuals. Also, it contributes to understand the properties on which it helps for increasing the investment in improving the social resilience in case we mention the majority of people that got a raised score to the same given property. As a result, this fits onto despite the trauma.

\section{CONCLUSION}

The study examines the relevance of observed properties on social resilience according to targeted set by the researcher. This relevance is based on the dependencies between variables taken two by two whose the interpretation of correlogram requires the contributions of the modalities about properties of resilience. The strong dependence observed between variables confirms this set which is composed of all fundamental impact strength. So, it propounds a confirmatory approach in case the researcher has theoretical prejudices on chosen variables to its study.

Another section of this work has been the mathematical modeling of resilience of individual from the fundamental set of constituted properties. This modeling on which a part here increases an automatic process of analysis on impact strength from data processing models. 


\section{REFERENCES}

[1] Tufféry S. (2007). Data Mining et statistique décisionnelle : intelligence des données. Editions TECHNIP 27 rue Ginoux 75737 PARIS Cedex 15, F. (Ed.).

[2] Gakuba T.-O. (1998). Les répercussions de la guerre et de l'exil sur l'identité de jeunes rwandais en France et en Suisse, recherche en cours dans le cadre d'une thèsede doctorat-Faculté de Psychologie et des Sciences de l'Education, Université de Genève.

[3] Kouadio-Odounfa A. (2014) Observatoire de Bouaké : approche de mesure et quelques résultats. [en ligne] 5eme Colloque de l'UMI Résilience (3 et 4 Décembre 2014).

[4] Achiepo O. Y. M. (2015). Les bases fondamentales de la Résilométrie, une science de modélisation de la souffrance. Ethiques Economiques/Ethics and Economics, 15.
[5] Mahieu F. R., Koffi K. J. \& Ballet. (2011). Face auxvulnérabilités, la résilience et ses limites. J.de Science Régionale de Langue Française, A. (Ed.)-Migrations et Territoires, 16.

[6] Samson C. (2005). La résilience- Hommes et Faits.

[7] Ambapour S. \& Bidoungaz R.(2012). Mesures de la pauvreté au Congo utilisant la logique floue. Journal Afrika Statistika, 7, 412-424.

[8] Baccini A. (2010). Statistique Descriptive Multidimensionnelle (pour les nuls). Institut de Mathématiques de Toulouse UMR CNRS 5219 Université Paul Sabatier -31062 -Toulouse cedex 9.

[9] Koffi K. J. (2014). Résilience et sociétés : Concepts et applications. Éthique et économique/Ethics and Economics, 11(1), 15. 